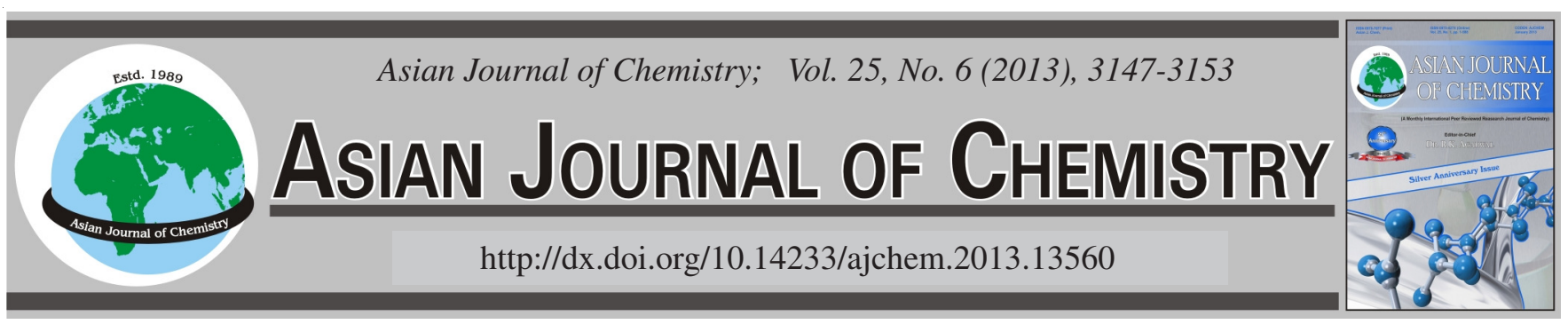

\title{
A Novel Electrochemical Sensor Based on Nanocomposite Film Electrode for Sensitive Determination of Environmental Hormone Bisphenol A
}

\author{
Jun-Hua Li*, Dai-Zhi Kuang, Yong-Lan Feng, Fu-Xing Zhang and Meng-Qin Liu
}

Key Laboratory of Functional Organometallic Materials of Hunan Province College, Department of Chemistry and Material Science, Hengyang Normal University, Hengyang 421008, Hunan Province, P.R. China

*Corresponding author: Fax: +86 734 8484195; Tel: +86 734 8484195; E-mail: junhua325@126.com

(Received: 6 February 2012;

Accepted: 14 December 2012)

AJC-12537

\begin{abstract}
Bisphenol-A (BPA) is an emerging contaminant with severe toxic effects such as disrupting endocrine system or causing cancer, therefore, developing sensitive and selective sensor for bisphenol-A is very important and interesting. Herein, mesoporous hydroxyapatite (meso$\mathrm{HAP})$ and mesoporous titanium dioxide $\left(m e s o-\mathrm{TiO}_{2}\right)$ have been synthesized and an electrochemical sensor for bisphenol-A was fabricated based on immobilizing meso-hydroxyapatite, meso- $\mathrm{TiO}_{2}$ and multi-walled carbon nanotubes (MWCNT) onto glassy carbon electrode (GCE) surface. Compared with bare electrode and single layer modified electrode, $m e s o-\mathrm{HAP} / m e s o-\mathrm{TiO}_{2} / \mathrm{MWCNT}_{\text {modified electrode }}$ not only significantly enhanced the oxidation peak current of bisphenol-A, but also lowered the oxidation overpotential, suggesting that the prepared sensor can remarkably improve the determining sensitivity of bisphenol-A. Factors influencing the detection processes were optimized and the kinetic parameters were also investigated. Under the optimized conditions, the oxidation peak current was proportional to bisphenol-A concentration in the range from $8.0 \times 10^{-9}-4.0 \times 10^{-7} \mathrm{M}$ with the correlation coefficient of 0.9979 . The detection limit was $1.0 \times 10^{-9} \mathrm{M}(\mathrm{S} / \mathrm{N}=3)$. The fabricated electrode showed good reproducibility, stability and antiinterference. The proposed method was successfully applied to determine bisphenol-A in plastic products and the results were satisfactory.
\end{abstract}

Key Words: Bisphenol-A, Electrochemical sensor, Hydroxyapatite, Titanium dioxide, Determination.

\section{INTRODUCTION}

Nowadays, the plastic industry applies bisphenol-A [2,2bis(4-hydroxyphenyl)propane, BPA] in producing epoxy resins and polycarbonate extensively ${ }^{1}$. However, it has been proved by many researches that bisphenol-A can disturb growth, development and reproduction by mimicking and interfering with hormonal activities ${ }^{2}$ and could possibly cause breast cancer, testicular cancer, diabetes, hyperactivity, obesity and low sperm counts ${ }^{3}$. Endocrine disruptors can disturb the secretion timing of natural hormone, which may cause procreation and grow problems, so endocrine disruptor detection is favoured by many researchers recently in view of health. Bisphenol-A can leach into food and environment when these plastic products are used for nursing bottle, food can linings and beverage container, etc. . $^{4,5}$. Thus, it is necessary and significant to monitor this important endocrine disrupting compound in trace.

There are some popular methods for determination of bisphenol-A such as solid-phase microextraction ${ }^{6}$, surface plasmon resonance biosensor ${ }^{7}$, high-performance liquid chromatography with UV detector (HPLC-UV) ${ }^{5,8}$, liquid chromatographic-tandem mass spectrometric (LC-MS/MS), fluorescence sensor ${ }^{10}$, flow injection inhibitory chemiluminescence method ${ }^{11}$ and molecular imprinting technique ${ }^{12}$. These methods have some advantages like high sensitivity and low detection, but they have many disadvantages such as timeconsuming pre-treatment steps, slow processing of multiple samples and complicated and expensive instrumentations, which result in on-site measurement impossible. Therefore, a new analytical technique with low cost, simple operation, time saving and real-time detection is needed. Under such situation, electrochemically analytical technique is a good choice to monitor lower concentration of bisphenol-A in environment. In conventional electrochemical analytical system, the working electrode needs surface modifying to improve the electrochemical responses. Recently, Yin et al. ${ }^{13}$ used poly-amidoamine and $\mathrm{Fe}_{3} \mathrm{O}_{4}$ magnetic nanoparticles modified electrode to investigate the electrochemical behaviours of bisphenol-A and realize the determination of bisphenol-A with lower detection limit of $5 \mathrm{nM}$. Though many other modified electrodes based on thionine ${ }^{14}$, MWCNT/CoPc/SF ${ }^{15}, \mathrm{MWCNT} \mathrm{GNPs}^{16}$, $\mathrm{NiTPPS} /$ carbon natube ${ }^{17}, \mathrm{PAMAM} / \mathrm{AuNP} / \mathrm{SF}^{18}, \mathrm{Mg}-\mathrm{Al}-\mathrm{CO}_{3} /$ $\mathrm{LDH}^{19}$ and mesoporous silica ${ }^{20}$, have also been reported to 
detect bisphenol-A with satisfactory results. But it is still a challenge to fabricate a new electrochemical sensor based on excellent nanomaterials with simpler treatment and synthesis.

A novel electrochemical sensor for bisphenol-A was successfully fabricated in this work. The working electrode of this sensor was modified with multi-walled carbon nanotubes (MWCNT), mesoporous hydroxyapatite (meso-HAP) and mesoporous titanium dioxide $\left(\right.$ meso- $\left.\mathrm{TiO}_{2}\right)$ for improve determination sensitivity and selectivity. MWCNT was treated by strong acid before use. Meso-HAP and meso- $\mathrm{TiO}_{2}$ were synthesized through preferable preparation routes. The electrooxidation peak of bisphenol-A was greatly increased at meso$\mathrm{HAP} /$ meso- $\mathrm{TiO}_{2} / \mathrm{MWCNT}$ modified electrode and it can be used an analytical sign for bisphenol-A determination. The experimental parameters were optimized and the kinetic parameters of the electrode process were also calculated. Finally, this sensor was applied to determine trace amounts of bisphenol-A in several plastic samples and the recoveries were satisfactory.

\section{EXPERIMENTAL}

MWCNT (purity > $95 \%$ ) were obtained from Shenzhen Nanotech Port Co. Ltd. (Shenzhen, China). Before use, MWCNT were refluxed for $5 \mathrm{~h}$ in concentrated solution $\mathrm{HNO}_{3} /$ $\mathrm{H}_{2} \mathrm{SO}_{4}$ (1/3 by volume), followed by filtering, rinsing with redistilled water and drying in air. $\mathrm{Meso}-\mathrm{TiO}_{2}$ was prepared by using the hydrolysis condensation method with non-ionic surfactant Triton X-100 as a template according to the literature $^{21}$. Meso-HAP was successfully prepared from $\mathrm{Ca}\left(\mathrm{NO}_{3}\right)_{2} \cdot 4 \mathrm{H}_{2} \mathrm{O}$ and $\mathrm{NH}_{4} \mathrm{H}_{2} \mathrm{PO}_{4}$ using surfactant cetyltrimethyl ammonium bromide as a template according to the literature ${ }^{22}$. BisphenolA was purchased from Sigma-Aldrich. The bisphenol-A stock solution of $0.01 \mathrm{M}$ was prepared by dissolving the required amount of bisphenol-A in ethanol and kept in darkness at $4{ }^{\circ} \mathrm{C}$. Working solutions were freshly prepared before use by diluting the stock solution. A phosphate buffer solution (PBS, pH 7.0) of $0.1 \mathrm{M}$ was always employed as a supporting electrolyte. Solutions were deaerated by bubbling high-purity nitrogen before the experiments. Unless otherwise stated, all chemicals and reagents used were of analytical reagent grade and all of the chemicals and reagents were used without further purification. All solutions were prepared with redistilled water.

All electrochemical experiments were performed on a CHI660D electrochemical workstation (Shanghai Chenhua Co. Ltd., Shanghai, China) with a conventional three-electrode cell. A bare or modified glassy carbon electrode (GCE) was used as working electrode. A saturated calomel electrode (SCE) and a platinum wire were used as reference electrode and auxiliary electrode, respectively. The $\mathrm{pH}$ measurements were carried out on PHS-3C exact digital pH metre (Shanghai REX Instrument Factory, Shanghai, China), which was calibrated with standard $\mathrm{pH}$ buffer solutions. All the measurements were carried out at room temperature.

Preparation of meso-HAP/meso-TiO $/$ $_{2} / \mathrm{MWCNT/GCE:}$ Before modification, a bare GCE ( $3 \mathrm{~mm}$ in diameter) was polished to form a mirror-like surface with 0.3 and $0.05 \mu \mathrm{m}$ alumina slurry on micro-cloth pads, then washed successively with $\mathrm{HNO}_{3}$ (1/1 by volume), anhydrous alcohol and redistilled water in an ultrasonic bath and dried in air before use. For fabrication of modified electrodes, the modifier suspension was prepared by dispersing $6 \mathrm{mg}$ mixture of meso- $\mathrm{TiO}_{2}$, mesoHAP and MWCNT (1/1/1 by mass) in $3 \mathrm{~mL}$ ethanol under ultrasonication for $0.5 \mathrm{~h}$. This suspension of $5 \mu \mathrm{L}$ was coated onto the GCE surface using a micropipette, followed by evaporating the solvent under an infrared lamp. The obtained electrode was denoted as meso-HAP/meso-TiO $/$ MWCNT/GCE. For comparison, the MWCNT/GCE, meso-HAP/GCE and meso- $\mathrm{TiO}_{2} / \mathrm{GCE}$ were independently prepared by the similar procedures as described previously. All the modified electrodes were stored at $4{ }^{\circ} \mathrm{C}$ in a refrigerator when they were not used.

Preparation of bisphenol-A solution: Five kinds of plastic products were purchased from a local supermarket. These samples were first cut into small pieces and washed twice with redistilled water. Then the plastic products were treated as following process to obtain sample solutions. Plastic product pieces $(10 \mathrm{~g})$ and redistilled water $(40 \mathrm{~mL})$ were added into a beaker and sealed with fresh keeping film. Then the sample was ultrasonicated for $0.5 \mathrm{~h}$ and immersed in $60{ }^{\circ} \mathrm{C}$ constant temperature water bath for $48 \mathrm{~h}$. After filtrated, the liquid phase was collected in a $100 \mathrm{~mL}$ volumetric flask. The extraction process was repeated two times and the extract solutions were also collected in the same volumetric flask. Finally, the extract solution was diluted to $100 \mathrm{~mL}$ with redistilled water. Otherwise, the spiked sample solution was prepared as the same method after adding known-amount of bisphenol-A standard solution.

\section{RESULTS AND DISCUSSION}

Cyclic voltammetric behaviours of bisphenol-A: Fig. 1 shows the CVs of $0.5 \mathrm{mM}$ bisphenol-A in 0.1 M PBS (pH 7.0) obtained at GCE (a), meso-HAP/GCE (b), MWCNT/GCE (c), meso- $\mathrm{TiO}_{2} / \mathrm{GCE}(\mathrm{d})$ and meso-HAP/meso-TiO $/ \mathrm{MWCNT} /$ GCE (e). It is suggested that the oxidation of bisphenol-A at these electrodes is totally irreversible under these experimental conditions, which is in agreement with previous reports ${ }^{13-20}$. The oxidation currents of bisphenol-A on the HAP/GCE and MWCNT/GCE were higher than that at the bare GCE, indicating that meso-HAP and MWCNT had obviously electrocatalytic activity towards the bisphenol-A oxidation due to their increased adsorption sites and the larger effective surface areas. When meso- $\mathrm{TiO}_{2}$ were immobilized on GCE surface, a higher current response for the oxidation of bisphenol-A was observed compared with the bare GCE, meso-HAP/GCE and MWCNT/GCE, which could be attributed to electrostatic adsorption between the positively charged $\mathrm{TiO}_{2}$ and the negatively charged bisphenol-A. It is well recognized that the surface of $\mathrm{TiO}_{2}$ in an aqueous environment takes electric charges that are dependent on $\mathrm{pH}$ and the surface charge is positive at acidic and neutral conditions due to the presence of $\equiv \mathrm{TiOH}_{2}{ }^{+}$groups ${ }^{23,24}$. Furthermore, the current response was much higher at meso-HAP/meso- $\mathrm{TiO}_{2} / \mathrm{MWCNT} / \mathrm{GCE}$ than those at other electrodes, which could be attributed to the synergistic effect of meso- $\mathrm{TiO}_{2}$, meso-HAP and MWCNT, leading to increase the determination sensitivity and decrease the limit of detection. In addition, the oxidation potential obtained at $\mathrm{TiO}_{2} / \mathrm{HAP} / \mathrm{MWCNT} / \mathrm{GCE}(0.718 \mathrm{~V})$ was lower 


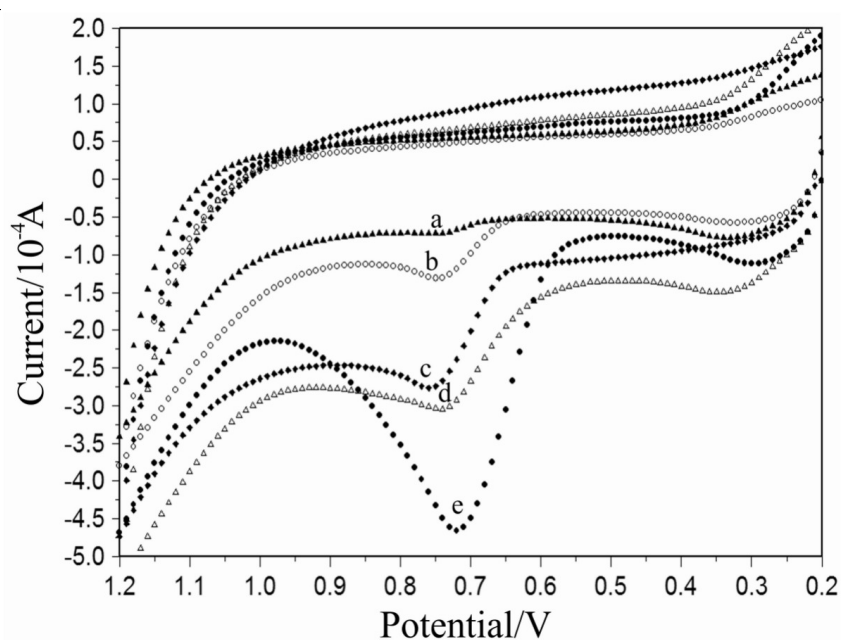

Fig. 1. CVs of $0.5 \mathrm{mM}$ bisphenol-A (a) GCE, (b) meso-HAP/GCE, (c) MWCNT/GCE, (d) $m e s o-\mathrm{TiO}_{2} / \mathrm{GCE}$ and (e) $m e s o-\mathrm{HAP} / m e s o-\mathrm{TiO}_{2} /$ MWCNT/GCE in 0.1 M PBS (pH 7.0). Scan rate: $50 \mathrm{mV} \mathrm{s}^{-1}$, accumulation potential: $-0.2 \mathrm{~V}$, accumulation times: $180 \mathrm{~s}$

than that at meso- $\mathrm{TiO}_{2} / \mathrm{GCE}(0.744 \mathrm{~V}), \mathrm{MWCNT} / \mathrm{GCE}(0.753$ $\mathrm{V}), \mathrm{HAP} / \mathrm{GCE}(0.748 \mathrm{~V})$ and $\mathrm{GCE}(0.758 \mathrm{~V})$, resulting from the synergistic effect produced by meso- $\mathrm{TiO}_{2}$, meso-HAP and MWCNT, suggesting that the interference of determination could be reduced. The oxidation potential of bisphenol-A at meso-HAP/meso- $\mathrm{TiO}_{2} / \mathrm{MWCNT/GCE}$ was also smaller than those in previous reports under near-neutral $\mathrm{pH}$ conditions, such as $\mathrm{Si} /$ boron-doped electrode $(1.20 \mathrm{~V} \text { vs. SCE })^{25}$ and $\mathrm{Pt}$ electrode $(0.89 \mathrm{~V} v s \text {. SCE })^{26}$. Therefore, a substantial decrease in oxidation overpotential has been achieved in the present study with meso-HAP/meso- $\mathrm{TiO}_{2} / \mathrm{MWCNT/GCE}$. However, the oxidation potential of bisphenol-A in this work was bigger than that at MWCNT/CoPc/SF/GCE (0.625 V vs. SCE $)^{15}$ and poly-amidoamine/ $\mathrm{Fe}_{3} \mathrm{O}_{4} / \mathrm{GCE}(0.541 \mathrm{~V} v s . \mathrm{SCE})^{13}$. The difference of the oxidation potential of bisphenol-A might be attributed to the matrix electrode, supporting electrolyte, modification procedure and modified materials.

Effect of meso-HAP/meso-TiO//MWCNT concentration: Fig. 2 depicts the influence of concentration of meso-HAP/ meso- $\mathrm{TiO}_{2} / \mathrm{MWCNT}$ on the oxidation peak current of $0.5 \mathrm{mM}$ bisphenol-A. As gradually improving the content of meso$\mathrm{HAP} /$ meso- $\mathrm{TiO}_{2} / \mathrm{MWCNT}$ from $0-2 \mathrm{mg} \mathrm{mL}^{-1}$, the peak current of bisphenol-A greatly enhances. With increasing the content of $m e s o-\mathrm{HAP} / m e s o-\mathrm{TiO}_{2} / \mathrm{MWCNT}$, the effective surface area and the accumulation efficiency also improve. Consequently, the surface concentration of bisphenol-A increases and then the oxidation peak current also enhances. When further increasing the content from 2 to $5 \mathrm{mg} \mathrm{mL}^{-1}$, the oxidation peak current of bisphenol-A increases slightly, suggesting that if the nanocomposite film is too thick, it is not beneficial for bisphenol-A sensing. In this work, the best content of meso-HAP/meso$\mathrm{TiO}_{2} / \mathrm{MWCNT}$ is selected as $2 \mathrm{mg} \mathrm{mL}^{-1}$.

Effect of pH: The effect of $\mathrm{pH}$ on the current response of meso-HAP/meso- $\mathrm{TiO}_{2} / \mathrm{MWCNT} / \mathrm{GCE}$ to $0.5 \mathrm{mM}$ bisphenolA was investigated in the $\mathrm{pH}$ range from 4-9. As shown in Fig. $3 \mathrm{~A}$, the oxidation peak current gradually increased with the increase of $\mathrm{pH}$ value from 4-7. When $\mathrm{pH}$ value improved, the electrochemical oxidation of bisphenol-A became much easier, so the peak current gradually increased. However, the oxidation



Fig. 2. Effect of meso-HAP/meso-TiO $/$ MWCNT concentration on the peak current of $0.5 \mathrm{mM}$ bisphenol-A


Fig. 3. (A) CVs of $0.5 \mathrm{mM}$ bisphenol-A at meso-HAP/meso- $\mathrm{TiO}_{2} / \mathrm{MWCNT} /$ GCE under different pH. a-f: 4, 5, 6, 7, 8 and 9. (B) Effect of $\mathrm{pH}$ on the oxidation current and oxidation potential

signal of bisphenol-A gradually decreased as further increasing $\mathrm{pH}$ value from 7-9, may be caused by the fact that the activity of sensor lowered at higher $\mathrm{pH}$ value. Undoubtedly, determination of bisphenol-A at $\mathrm{pH} 7$ has the highest sensitivity. Moreover, the background current was relatively low and the oxidation peak was well shaped at $\mathrm{pH} 7$. In high $\mathrm{pH}$ condition $(\mathrm{pH}>7)$, the amount of negative charge in meso-HAP/meso$\mathrm{TiO}_{2} / \mathrm{MWCNT}$ would increase because of $\equiv \mathrm{TiO}^{-}$groups presented in the $\mathrm{TiO}_{2}$ surface ${ }^{23,24}$. This would reduce the adsorption of bisphenol-A, leading to decrease the current response. 
Moreover, the maximum response to $\mathrm{pH}$ was lower than the $\mathrm{pKa}$ of bisphenol-A $\left(\mathrm{pK}_{\mathrm{a}}=9.73\right)^{27}$, which indicated that in this way the non-dissociated bisphenol-A can be adsorbed better than the dissociated bisphenol-A on the sensor surface. Therefore, considering the sensitivity of bisphenol-A determination, a $\mathrm{pH}$ value of 7 was chosen for the subsequent analytical experiments.

The relationship between the oxidation peak potential $\left(\mathrm{E}_{\mathrm{pa}}\right)$ and $\mathrm{pH}$ was also shown in Fig. 3B. A linear shift of $\mathrm{E}_{\mathrm{pa}}$ towards negative potential with an increasing $\mathrm{pH}$ indicated that protons were directly involved in the oxidation of bisphenolA. It obeyed the following equation: $\mathrm{E}_{\mathrm{pa}}(\mathrm{V})=-0.0505 \mathrm{pH}+$ $0.9622\left(\mathrm{R}^{2}=0.9825\right)$. The slope is approximately close to the theoretical value of $-57.6 \mathrm{mV} \mathrm{pH}^{-1}$, indicating that the electron transfer was accompanied by an equal number of protons in electrode reaction.

Scan rate effect: The effect of scan rate on the oxidation of bisphenol-A was also investigated. Fig. 4A showed CVs of $0.5 \mathrm{mM}$ bisphenol-A at meso-HAP/meso-TiO $/ \mathrm{MWCNT}_{2} \mathrm{MCE}$ with different scan rates. The oxidation peak current increased gradually with the increase of scan rate. As shown in Fig. 4B, the oxidation peak current increased linearly with the square root of scan rate in the range of $40-300 \mathrm{mV} \mathrm{s}^{-1}$ and can be expressed as: $\mathrm{I}_{\mathrm{pa}}\left(10^{-4} \mathrm{~A}\right)=-0.2687 \mathrm{v}^{1 / 2}\left(\mathrm{mV} \mathrm{s}^{-1}\right)+0.8892\left(\mathrm{R}^{2}=\right.$ $0.9892)$, which indicated that the oxidation of bisphenol-A on meso-HAP/meso- $\mathrm{TiO}_{2} / \mathrm{MWCNT/GCE}$ is a typical diffusioncontrolled process. In addition, with increasing scan rate, the anodic peak potential $\left(\mathrm{E}_{\mathrm{pa}}\right)$ shifted positively. The relationship between $\mathrm{E}_{\mathrm{pa}}$ and the natural logarithm of scan rate (ln $v$ ) was shown in Fig. 4C. It can be seen that $\mathrm{E}_{\mathrm{pa}}$ changed linearly versus $\ln \mathrm{v}$ with a linear regression equation of $\mathrm{E}_{\mathrm{pa}}=0.0547 \ln \mathrm{v}+$ $0.4518\left(\mathrm{v}, \mathrm{mV} \mathrm{s}^{-1}, \mathrm{R}^{2}=0.9607\right)$ in the range from $40-300 \mathrm{mV}$ $\mathrm{s}^{-1}$. For a totally irreversible electrode process, the relationship between the potential $\left(\mathrm{E}_{\mathrm{p}}\right)$ and scan rate $(v)$ could be expressed as eqn. 1 given by Laviron $^{28}$ :

$$
\mathrm{E}_{\mathrm{p}}=\mathrm{E}^{0}+\left(\frac{\mathrm{RT}}{\alpha \mathrm{nF}}\right) \ln \left(\frac{\mathrm{RTk}^{0}}{\alpha \mathrm{nF}}\right)+\left(\frac{\mathrm{RT}}{\alpha \mathrm{nF}}\right) \ln \alpha
$$

where $\alpha$ is the electron transfer coefficient, $\mathrm{n}$ is the number of transfer electron, $\mathrm{R}, \mathrm{T}$ and $\mathrm{F}$ have their usual meanings. Thus, $\alpha_{n}$ was calculated to be 0.46 . Generally, $\alpha$ is assumed to be 0.5 in a totally irreversible electrode process. So, the number of transfer electron $(n)$ in the electro-oxidation of bisphenol$\mathrm{A}$ is 1 . The $\mathrm{pH}$ effect on $\mathrm{E}_{\mathrm{pa}}$ demonstrated that the number of

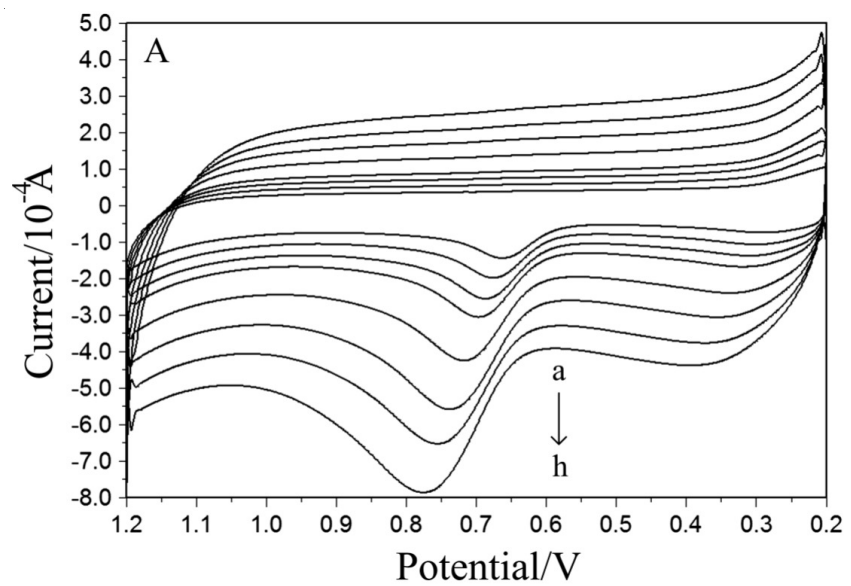

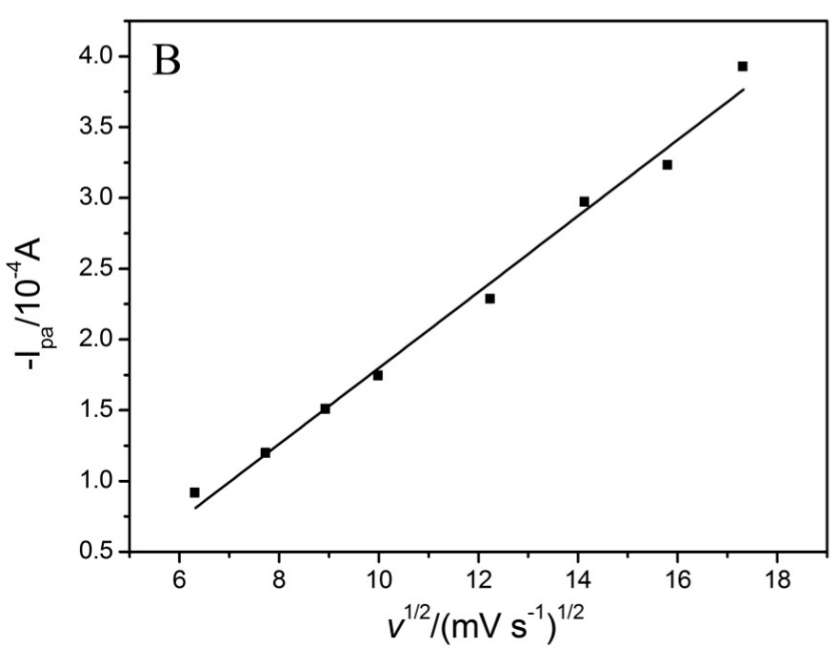

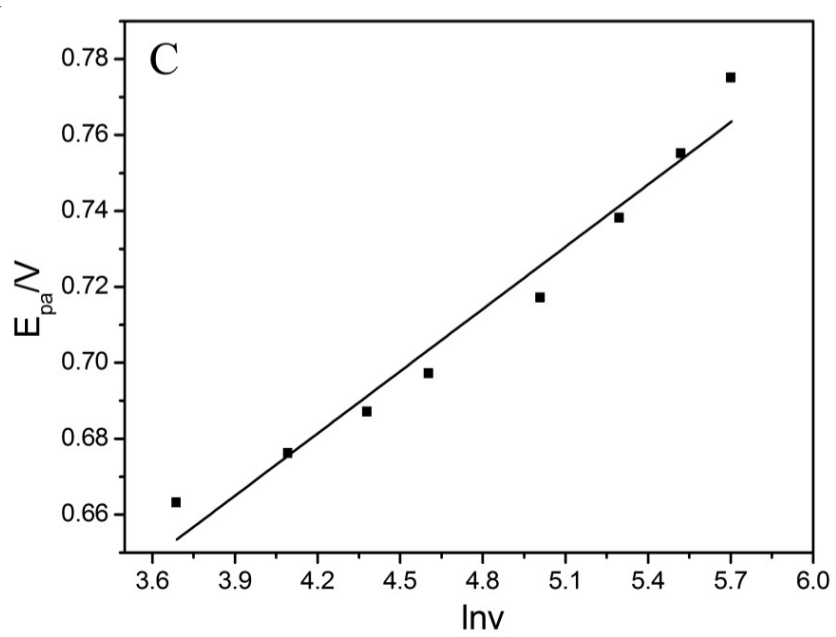

Fig. 4. (A) $\mathrm{CVs}$ of $0.5 \mathrm{mM}$ bisphenol-A at meso-HAP/meso- $\mathrm{TiO}_{2} / \mathrm{MWCNT} /$ GCE with different scan rates. Curves a-h is obtained at 40, 60, 80, $100,150,200,250$ and $300 \mathrm{mV} \mathrm{s}^{-1}$, respectively. (B) Plot for the dependence of peak current on the square root of scan rate. (C) Relationship between $\mathrm{E}_{\mathrm{pa}}$ and $\ln \mathrm{v}$

electrons and protons involved in the bisphenol-A oxidation process is equal. Therefore, the electrooxidation of bisphenolA on $m e s o-\mathrm{HAP} / m e s o-\mathrm{TiO}_{2} / \mathrm{MWCNT} / \mathrm{GCE}$ is a one-electron and one-proton process.

Effect of accumulation conditions: Accumulation can improve the amount of bisphenol-A absorbed on the electrode surface and then improve determination sensitivity and decrease detection limit. In order to evaluate the influence of accumulation potential on determination of bisphenol-A, the oxidation peak currents of $0.5 \mathrm{mM}$ bisphenol-A after $180 \mathrm{~s}$ accumulation under different accumulation potentials were measured by differential pulse voltammetry (DPV). The oxidation peak current increase remarkably when the accumulation potential shifts from 0.30 to $-0.20 \mathrm{~V}$. However, the decreased oxidation peak current was obtained under more negative accumulation potential. Therefore, an accumulation potential of $-0.20 \mathrm{~V}$ was selected as an optimum accumulation potential for determination of bisphenol-A. In addition, the oxidation peak current increased gradually with accumulation time up to $180 \mathrm{~s}$ at a fixed accumulation potential of $-0.20 \mathrm{~V}$. More bisphenol-A could be adsorbed on the electrode surface with extending accumulation time. Afterwards, the peak current increased 
much slightly as further increasing accumulation time. This phenomenon could be attributed to the saturated adsorption of bisphenol-A at the electrode surface. Considering both sensitivity and work efficiency, the optimal accumulation time of $180 \mathrm{~s}$ was employed in the further experiments.

Electrochemically effective surface area and $\mathbf{k}_{\mathbf{s}}$ : The electrochemically effective surface areas of the bare GCE and meso-HAP/meso- $\mathrm{TiO}_{2} / \mathrm{MWCNT} / \mathrm{GCE}$ can be calculated by the slopes of the plot of $\mathrm{Q}$ versus $\mathrm{t}^{1 / 2}$ obtained by chronocoulometry (Fig. 5) using $0.1 \mathrm{mM} \mathrm{K}_{3}\left[\mathrm{Fe}(\mathrm{CN})_{6}\right]$ as model complex based on eqn. 2 given by Anson ${ }^{29}$ :

$$
\mathrm{Q}(\mathrm{t})=\frac{2 \mathrm{nFAcD}}{\pi^{1 / 2} \mathrm{~T}^{1 / 2}}+\mathrm{Q}_{\mathrm{dl}}+\mathrm{Q}_{\mathrm{ads}}
$$

where $\mathrm{A}$ is surface area of working electrode, $\mathrm{c}$ is concentration of substrate, $\mathrm{D}$ is diffusion coefficient ( $\mathrm{D}$ of $\mathrm{K}_{3}\left[\mathrm{Fe}(\mathrm{CN})_{6}\right]$ is $\left.7.6 \times 10^{-6} \mathrm{~cm}^{2} \mathrm{~s}^{-1}\right), \mathrm{Q}_{\mathrm{dl}}$ is double layer charge which could be eliminated by background subtraction, $\mathrm{Q}_{\mathrm{ads}}$ is Faradaic charge. Other symbols have their usual meanings. Based on the slope of the linear relationship between $\mathrm{Q}$ and $\mathrm{t}^{1 / 2}$, A could be calculated to be 0.0746 and $0.1619 \mathrm{~cm}^{2}$ for GCE and meso-HAP/meso$\mathrm{TiO}_{2} / \mathrm{MWCNT} / \mathrm{GCE}$, respectively. The results indicated that the effective surface area of the electrode was increased obviously after electrode modification, which would increase the adsorption capacity of bisphenol-A, leading to enhance current response and decrease detection limit. The diffusion coefficient (D) and Faradic charge $\left(\mathrm{Q}_{\mathrm{ads}}\right)$ of bisphenol-A at meso-HAP/ meso- $\mathrm{TiO}_{2} / \mathrm{MWCNT/GCE}$ can also be determined using chronocoulometry based on enq. 2 . After background subtraction, the plot of $\mathrm{Q}$ against $\mathrm{t}^{1 / 2}$ showed a linear relationship with slope of $2.353 \times 10^{-3}$ and $\mathrm{Q}_{\text {ads }}$ of $1.191 \times 10^{-4} \mathrm{C}$. As $\mathrm{n}=1, \mathrm{~A}=$ $0.1619 \mathrm{~cm}^{2}$ and $\mathrm{c}=0.5 \mathrm{mM}$, D was calculated to be $7.108 \times$ $10^{-6} \mathrm{~cm}^{2} \mathrm{~s}^{-1}$. According to the equation of $\mathrm{Q}_{\mathrm{ads}}=\mathrm{nFA} \Gamma_{\mathrm{s}}$, the adsorption capacity, $\Gamma_{\mathrm{s}}$, could be obtained as $7.623 \times 10^{-9} \mathrm{~mol}$ $\mathrm{cm}^{-2}$ which was much greater than that of poly-amidoamine/ $\mathrm{Fe}_{3} \mathrm{O}_{4} / \mathrm{GCE}^{13}$, PAMAM/AuNPs/SF/GCE ${ }^{18}$ and $\mathrm{Mg}-\mathrm{Al}-\mathrm{CO}_{3} /$ $\mathrm{LDH} / \mathrm{GCE}^{19}$. The standard heterogeneous rate constant $\left(\mathrm{k}_{\mathrm{s}}\right)$ for totally irreversible oxidation of bisphenol-A at the modified electrode was calculated based on eqn. $3^{30}$ :

$$
\mathrm{k}_{\mathrm{s}}=2.415 \exp \left(\frac{-0.02 \mathrm{~F}}{\mathrm{RT}}\right) \mathrm{D}^{1 / 2}\left(\mathrm{E}_{\mathrm{p}}-\mathrm{E}_{\mathrm{p} / 2}\right)^{-1 / 2} \mathrm{~V}^{1 / 2}
$$



Fig. 5. Plot of Q-t curves (insert: plot of Q-t $\mathrm{t}^{1 / 2}$ curves) of (a) GCE and (b) meso-HAP/meso- $\mathrm{TiO}_{2} / \mathrm{MWCNT} / \mathrm{GCE}$ in $0.1 \mathrm{mM} \mathrm{K}_{3}\left[\mathrm{Fe}(\mathrm{CN})_{6}\right]$ containing $0.1 \mathrm{M} \mathrm{KCl}$ and (c) meso-HAP/meso-TiO $/ \mathrm{MWCNT} / \mathrm{GCE}$ in $0.1 \mathrm{M}$ pH 7.0 PBS in the presence of $0.5 \mathrm{mM}$ bisphenol-A where $\mathrm{E}_{\mathrm{p}}$ and $\mathrm{E}_{\mathrm{p} / 2}$ represent the peak potential and the potential at which $\mathrm{I}=\mathrm{I}_{\mathrm{p} / 2}$ in linear sweep voltammetry (LSV), respectively. Other symbols have their usual meanings. In this work, $\mathrm{E}_{\mathrm{p}}-\mathrm{E}_{\mathrm{p} / 2}=62 \mathrm{mV}, \mathrm{D}=7.108 \times 10^{-6} \mathrm{~cm}^{2} \mathrm{~s}^{-1}, \mathrm{v}=50 \mathrm{mV} \mathrm{s}^{-1}$ and $\mathrm{T}=293 \mathrm{~K}$. Therefore, $\mathrm{k}_{\mathrm{s}}$ was calculated to be $3.904 \times 10^{-3} \mathrm{~cm}$ $\mathrm{s}^{-1}$, which was bigger than that of $1.08 \times 10^{-3} \mathrm{~cm} \mathrm{~s}^{-1}$ at PAMAM/ AuNPs/SF/GCE ${ }^{18}$ or $2.5 \times 10^{-3} \mathrm{~cm} \mathrm{~s}^{-1}$ at $\mathrm{Mg}-\mathrm{Al}-\mathrm{CO}_{3} / \mathrm{LDH} /$ $\mathrm{GCE}^{19}$, indicating a relative fast electrode reaction process under our experimental conditions.

Analytical application: The determination of bisphenolA concentration using meso-HAP/meso- $\mathrm{TiO}_{2} / \mathrm{MWCNT} / \mathrm{GCE}$ was performed with DPV (Fig. 6). The results showed that the anodic peak current $\left(\mathrm{I}_{\mathrm{pa}}\right)$ was proportional to bisphenol-A concentration in the range of $8.0 \times 10^{-9}-4.0 \times 10^{-7} \mathrm{M}$. The linear regression equation can be expressed as $\mathrm{I}_{\mathrm{pa}}\left(10^{-7} \mathrm{~A}\right)=0.03669 \mathrm{C}$ $\left(10^{-9} \mathrm{M}\right)+8.8219$, with a correlation coefficient of 0.9979 . The linear range was broader in low concentration edge than the reported ranges obtained from some modified electrodes such as PAMAM/ $/ \mathrm{Fe}_{3} \mathrm{O}_{4} / \mathrm{GCE}^{13}$, thionine/CPE ${ }^{14}$, MWCNT/ $\mathrm{CoPc} / \mathrm{SF} / \mathrm{GCE}^{15}$ and $\mathrm{Mg}-\mathrm{Al}-\mathrm{CO}_{3} / \mathrm{LDH} / \mathrm{GCE}^{19}$. The detection $\operatorname{limit}(\mathrm{S} / \mathrm{N}=3)$ is estimated to be $1 \times 10^{-9} \mathrm{M}$, lower than that from HPLC-UV ${ }^{3}$, fluorescence sensor ${ }^{5}$, flow-injection chemiluminescence method ${ }^{6}$ and many other modified electrodes ${ }^{14-18,20,31,32}$. A detailed comparison of the performance of different electrochemical methods for the determination of bisphenol-A is summarized in Table-1. It can be concluded that the meso$\mathrm{HAP} /$ meso- $\mathrm{TiO}_{2} / \mathrm{MWCNT} / \mathrm{GCE}$ is an excellent platform for the detection of bisphenol-A.

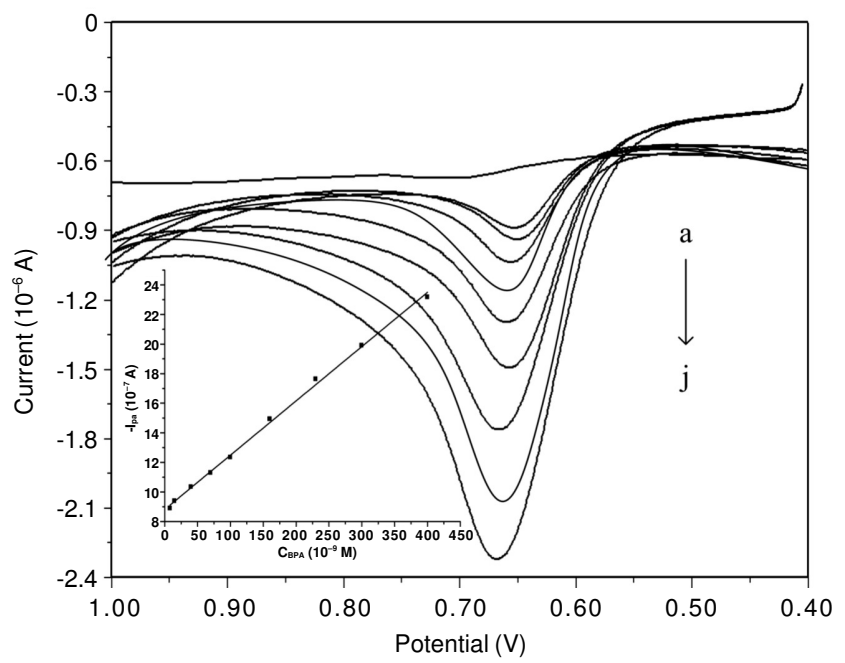

Fig. 6. DPV curves of bisphenol-A at meso-HAP/meso- $\mathrm{TiO}_{2} / \mathrm{MWCNT/}$ GCE in 0.1 M PBS (pH 7.0) containing different concentrations of bisphenol-A (a-j: 0, 0.008, 0.015, 0.040, 0.070, 0.100, 0.160, 0.230, $0.300,0.400 \mu \mathrm{M})$. Insert: calibration curve. Amplitude: $0.05 \mathrm{~V}$; pulse width: $0.05 \mathrm{~s}$; pulse period: $0.2 \mathrm{~s}$; accumulation potential: $-0.2 \mathrm{~V}$; accumulation times: $180 \mathrm{~s}$

To demonstrate its suitability and potential for sample analysis, this method was used to determine bisphenol-A in five kinds of plastic products (nursing bottle, milk container, mineral water bottle, food can linings, beverage container). Under the optimized conditions, a certain volume of sample solution was added into $\mathrm{pH}$ 7.0 PBS and then analyzed according to the above described procedure. To study the accuracy of the proposed method, recovery experiments were carried 


\begin{tabular}{|c|c|c|c|c|c|c|c|}
\hline \multicolumn{8}{|c|}{$\begin{array}{c}\text { TABLE-1 } \\
\text { PERFORMANCE COMPARISON OF PRESENT SENSOR FOR BISPHENOL-A } \\
\text { DETECTION WITH OTHER ELECTROCHEMICAL SENSORS }\end{array}$} \\
\hline Sensor & $\begin{array}{c}\text { Linear range } \\
(\mu \mathrm{M})\end{array}$ & $\begin{array}{l}\text { Detection } \\
\text { limit (nM) }\end{array}$ & Recovery (\%) & $\Gamma_{\mathrm{s}}\left(\mathrm{mol} \mathrm{cm} \mathrm{cm}^{-2}\right)$ & $\mathrm{k}_{\mathrm{s}}\left(\mathrm{cm} \mathrm{s}^{-1}\right)$ & Stability & Ref. \\
\hline $\mathrm{HAP} / \mathrm{TiO}_{2} / \mathrm{MWCNT} / \mathrm{GCE}$ & $0.008-0.4$ & 1 & $98.78-104.81$ & $7.623 \times 10^{-9}$ & $3.904 \times 10^{-3}$ & $87 \%$ (30 days) & This study \\
\hline $\mathrm{PAMAM}^{\mathrm{a}} / \mathrm{Fe}_{3} \mathrm{O}_{4} / \mathrm{GCE}$ & $0.01-3.07$ & 5 & $95.3-104$ & $4.22 \times 10^{-11}$ & $3.16 \times 10^{-3}$ & $86 \%$ (30 days) & [13] \\
\hline Thionine/CPE & $0.15-45$ & 150 & - & - & - & - & [14] \\
\hline $\mathrm{MWCNT} / \mathrm{CoPc}^{\mathrm{b}} / \mathrm{SF}^{\mathrm{c}} / \mathrm{GCE}$ & $0.05-3$ & 30 & $95.36-104.39$ & - & - & $75 \%$ (30 days) & [15] \\
\hline MWCNT/GNPs/GCE & $0.02-20$ & 7.5 & $93.8-103.1$ & - & - & - & [16] \\
\hline NiTPPS/carbon nanotube/GCE & $0.05-50$ & 15 & $96-104$ & $2.2 \times 10^{-9}$ & - & - & [17] \\
\hline PAMAM-GNPs - SF/GCE & $0.001-1.3$ & 0.5 & $97-105$ & $1.01 \times 10^{-11}$ & $1.08 \times 10^{-3}$ & $91.4 \%$ (14 days) & [18] \\
\hline $\mathrm{Mg}-\mathrm{Al}-\mathrm{CO}_{3} / \mathrm{LDH}^{\mathrm{f}} / \mathrm{GCE}$ & $0.01-1.05$ & 5 & $96.06-104.9$ & $1.10 \times 10^{-11}$ & $2.5 \times 10^{-3}$ & $92 \%$ (15 days) & [19] \\
\hline Mesoporous silica & $0.22-8.8$ & 38 & $91.3-107.2$ & - & - & - & [20] \\
\hline $\mathrm{CoPc} / \mathrm{CPE}$ & $0.0875-12.5$ & 10 & $92.1-107.8$ & $1.64 \times 10^{-11}$ & $2.65 \times 10^{-3}$ & $70 \%$ (25 days) & {$[31]$} \\
\hline $\mathrm{NiTAPc}^{\mathrm{g}} / \mathrm{Ni}-\mathrm{O}-\mathrm{Ni} /$ gold electrode & $700-30000$ & 3.68 & - & $1.11-5.46 \times 10^{-10}$ & - & - & [32] \\
\hline PAMAM/CoTe quantum dots/GCE & $0.013-9.89$ & 1 & $97-107.2$ & $2.41 \times 10^{-11}$ & $1.85 \times 10^{-3}$ & $72 \%$ (35 days) & [33] \\
\hline Carboxylated MWCNT/GCE & $0.01-10$ & 5 & $98.4-102.8$ & - & - & $82 \%$ (30 days) & [34] \\
\hline Acetylene black/DHP/GCE & $0.02-5$ & 6 & $98.6-99.2$ & - & - & $94.1 \%$ (21 days) & [35] \\
\hline ITO electrode & $5-120$ & 290 & - & - & - & - & [36] \\
\hline
\end{tabular}

${ }^{\mathrm{a}}$ PAMAM: poly-amidoamine. ${ }^{\mathrm{b}} \mathrm{CoPc}$ : cobalt phthalocyanine. ${ }^{\mathrm{c}} \mathrm{SF}$ : silk fibroin. ${ }^{\mathrm{d}} \mathrm{GNPs}$ : gold nanoparticles. ${ }^{\mathrm{e}} \mathrm{NiTPPS}$ : Ni(II)tetrakis(4sulfonatophenyl) porphyrin. ${ }^{\mathrm{f}} \mathrm{LDH}$ : layered double hydroxide. ${ }^{\mathrm{g}} \mathrm{NiTAPc}$ : Nickel tetraamino phthalocyanine. ${ }^{\text {h}} \mathrm{DHP}$ : dihexadecyl hydrogen phosphate.

TABLE-2

DETERMINATION OF BISPHENOL-A IN PLASTIC SAMPLES

\begin{tabular}{|c|c|c|c|c|c|c|c|c|}
\hline \multirow[b]{2}{*}{ Sample $^{\mathrm{a}}$} & \multicolumn{6}{|c|}{ Detected by this method } & \multirow[b]{2}{*}{$\begin{array}{l}\text { Detected by } \\
\operatorname{HPLC}^{\mathrm{b}}(\mathrm{nM})\end{array}$} & \multirow[b]{2}{*}{$\begin{array}{l}\text { Relative } \\
\text { error (\%) }\end{array}$} \\
\hline & $\begin{array}{c}\text { Measured } \\
(\mathrm{nM})\end{array}$ & $\begin{array}{c}\text { Added } \\
(\mathrm{nM})\end{array}$ & $\begin{array}{c}\text { Predicted } \\
(\mathrm{nM})\end{array}$ & $\begin{array}{l}\text { Found }^{\mathrm{b}} \\
\text { (nM) }\end{array}$ & $\begin{array}{l}\mathrm{RSD}^{\mathrm{c}} \\
(\%)\end{array}$ & $\begin{array}{c}\text { Recovery } \\
(\%)\end{array}$ & & \\
\hline Nursing bottle & 95 & 100 & 195 & 202 & 3.89 & 103.59 & 209 & -3.35 \\
\hline Milk container & 87 & 100 & 187 & 196 & 4.05 & 104.81 & 202 & -2.97 \\
\hline Mineral water bottle & 143 & 150 & 293 & 289 & 2.93 & 98.63 & 285 & 1.40 \\
\hline Food can linings & 158 & 150 & 308 & 305 & 3.62 & 99.03 & 295 & 3.39 \\
\hline Beverage container & 179 & 150 & 329 & 325 & 4.18 & 98.78 & 320 & 1.56 \\
\hline
\end{tabular}

${ }^{a}$ All the plastic samples were made in China. ${ }^{b}$ Mean of five measurements. ${ }^{c}$ Relative standard deviation for $\mathrm{n}=5$.

out by standard addition method. The percentage of the recovery values was calculated by comparing the concentration obtained from the samples with the totally actual and added concentrations. The results obtained are listed in Table- 2 . The recoveries were in the range 98.63-104.81\%, indicating that this method had good accuracy. For comparison, the bisphenol-A concentrations were also detected with HPLC and the results were also shown in Table-2. The analytical results obtained by both methods showed a good agreement (relative error $< \pm 5 \%$ ), suggesting that determination of bisphenol-A using this proposed sensor is feasible.

Reproducibility, stability and interference: The fabrication reproducibility for ten modified electrodes was carried out by comparing the oxidation peak current of $0.5 \mathrm{mM}$ bisphenol-A. The relative standard deviation (RSD) was 4.32 $\%$, revealing that this method had good reproducibility. The stability of the electrode was also investigated by measuring the electrode response with $0.5 \mathrm{mM}$ bisphenol-A every 10 days. Between measurements the electrode was stored at $4{ }^{\circ} \mathrm{C}$ in a refrigerator. The current response decreased to $94 \%$ after 10 days, while $90 \%$ of the original response retained after 20 days. The electrode still retained $87 \%$ of its original response even after 30 days. On the other hand, in order to evaluate the selectivity of the biosensor, the influence of some possible interfering substances was examined in $\mathrm{pH}$ 7.0 PBS solution containing $0.5 \mathrm{mM}$ bisphenol-A. The results suggested that 100-fold concentration of phenol, hydroquinone, hydroxyphenol, pyrocatechol, 4-nitrophenol, 2,4-dinitrophenol and dioctyl phthalate had no influence on the signals of bisphenolA with deviations below $5 \%$. Additionally, some inorganic ions such as 200-fold concentration of $\mathrm{Na}^{+}, \mathrm{K}^{+}, \mathrm{Mg}^{2+}, \mathrm{Ca}^{2+}$, $\mathrm{Ni}^{2+}, \mathrm{Co}^{2+}, \mathrm{Fe}^{3+}, \mathrm{Cl}^{-}, \mathrm{Br}^{-}, \mathrm{I}^{-}, \mathrm{NO}_{3}{ }^{-}, \mathrm{SO}_{4}{ }^{2-}$, have no influence on the signals of bisphenol-A with deviations below $5 \%$. The results obtained from reproducibility, stability and interference tests indicated that meso-HAP/meso- $\mathrm{TiO}_{2} / \mathrm{MWCNT/GCE}$ might be suitable for analytical application.

\section{Conclusion}

An electrochemical sensor for bisphenol-A was fabricated using meso-HAP/meso-TiO $/ \mathrm{MWCNT}$ as electrode modification materials and a novel sensitive and reliable electrochemical method was developed to determine trace amounts of environmental hormone bisphenol-A in plastic products. With the synergistic effect of the meso-HAP/meso- $\mathrm{TiO}_{2}$ / MWCNT, the oxidation peak current increased remarkably compared with meso-HAP/GCE, meso- $\mathrm{TiO}_{2} / \mathrm{GCE}$ and MWCNT/GCE. Moreover, this is the first time to report the determination of bisphenol-A at the meso-HAP/meso- $\mathrm{TiO}_{2} /$ MWCNT/GCE utilizing the oxidation signal of bisphenol-A. In addition, the fabricated sensor exhibited high sensitivity, good accuracy and acceptable stability. 


\section{ACKNOWLEDGEMENTS}

This work is kindly supported by the supports of the Open Fund Project of Key Laboratory in Hunan Universities (No. 12C0536, No. 10K010), the Youth Backbone Teacher Training Program (2010) and Key Laboratory Open Fund (No. $11 \mathrm{~K} 02$ ) of Hengyang Normal University.

\section{REFERENCES}

1. P. Palanza, L. Gioiosa, F.S. Vom-Saal and S. Parmigiani, Environ. Res. 108, 150 (2008)

2. H. Okada, T. Tokunaga, X.H. Liu, S. Takayanagi, A. Matsushima and Y. Shimohigashi, Environ. Health Perspect, 116, 32 (2008).

3. M. Yang, J.H. Ryu, R. Jeon, D. Kang and K.Y. Yoo, Arch. Toxicol., 83, 281 (2009).

4. H.H. Le, E.M. Carlson, J.P. Chua and S.M. Belcher, Toxicol. Lett., 176, 149 (2008).

5. A. Taskeen and I. Naeem, Asian J. Chem., 22, 4133 (2010).

6. T. Stoichev, M.S. Baptista, M.C.P. Basto, P.N. Carvalho and M.S.D. Vasconcelos, Anal. Bioanal. Chem., 391, 425 (2008).

7. K. Hegnerová, M. Piliarik, M. Šteinbachová, Z. Flegelová, H. Cernohorská and J. Homola, Anal. Bioanal. Chem., 398, 1963 (2010).

8. M.R. Hadjmohammadi and I. Saeidi, Monatsh. Chem., 141, 501 (2010).

9. R.S. Zhao, X. Wang and J.P. Yuan, J. Sep. Sci., 33, 1652 (2010).

10. X. Wang, H. Zeng, L. Zhao and J.M. Lin, Anal. Chim. Acta, 556, 313 (2006).

11. S.H. Wang, X.T. Wei, L.Y. Du and H.S. Zhuang, Luminescence, 20, 46 (2005).

12. Y. Ji, J. Yin, Z. Xu, C. Zhao, H. Huang, H. Zhang and C. Wang, Anal. Bioanal. Chem., 395, 1125 (2009).

13. H. Yin, L. Cui, Q. Chen, W. Shi, S. Ai, L. Zhu and L. Lu, Food Chem., 125, 1097 (2011).

14. M. Portaccio, D.D. Tuoro, F. Arduini, M. Lepore, D.G. Mita, N. Diano, L. Mita and D. Moscone, Biosens. Bioelectron., 25, 2003 (2010).

15. H. Yin, Y. Zhou, J. Xu, S. Ai, L. Cui and L. Zhu, Anal. Chim. Acta, 659
144 (2010).

16. X. Tu, L. Yan, X. Luo, S. Luo and Q. Xie, Electroanalysis, 21, 2491 (2009).

17. X. Liu, H. Feng, X. Liu and D.K.Y. Wong, Anal. Chim. Acta, 689, 212 (2011).

18. H. Yin, Y. Zhou, S. Ai, R. Han, T. Tang and L. Zhu, Microchim. Acta, 170, 99 (2010)

19. H. Yin, L. Cui, S. Ai, H. Fan and L. Zhu, Electrochim. Acta, 55, 603 (2010).

20. F. Wang, J. Yang and K. Wu, Anal. Chim. Acta, 638, 23 (2009).

21. Y. Wang and Z.H. Jiang, Mater. Sci. Eng. B, 128, 229 (2006).

22. H. Wang, L. Zhai, Y. Li and T. Shi, Mater. Res. Bull., 43, 1607 (2008).

23. M.R. Hoffmann, S.T. Martin, W. Choi and D.W. Bahnemann, Chem. Rev., 95, 69 (1995).

24. C. Kormann, D.W. Bahnemann and M.R. Hoffmann, Environ. Sci. Technol., 25, 494 (1991)

25. M. Murugananthan, S. Yoshihara, T. Rakuma and T. Shirakashi, J. Hazard. Mater., 154, 213 (2008).

26. M. Ngundi, O. Sadik, T. Yamaguchi and S. Suye, Electrochem. Commun., 5, 61 (2003).

27. H. Sambe, K. Hoshina, K. Hosoya and J. Haginaka, J. Chromatogr. A, 1134, 16 (2006).

28. E. Laviron, J. Electroanal. Chem., 52, 355 (1974).

29. F. Anson, Anal. Chem., 36, 932 (1964).

30. J. Velasco, Electroanalysis, 9, 880 (1997).

31. H. Yin, Y. Zhou and S. Ai, J. Electroanal. Chem., 626, 80 (2009).

32. V. Chauke, F. Matemadombo and T. Nyokong, J. Hazard. Mater., 178, 180 (2010).

33. H. Yin, Y. Zhou, S. Ai, Q. Chen, X. Zhu, X. Liu and L. Zhu, J. Hazard. Mater., 174, 236 (2010).

34. J. Li, D. Kuang, Y. Feng, F. Zhang and M. Liu, Microchim. Acta, 172, 379 (2011).

35. W. Huang and C. Yang, Anal. Lett., 40, 3280 (2007).

36. Q. Li, H. Li, G.F. Du and Z.H. Xu, J. Hazard. Mater., 180, 703 (2010). 